\title{
School Achievement and Sexual Abstinence: Positive Correlates for Adolescents?
}

\author{
Jennifer L. Brown ${ }^{1}$, Glennelle Halpin ${ }^{2}$, \& Gerald Halpin ${ }^{2}$ \\ ${ }^{1}$ College of Education and Health Professions, Columbus State University, Columbus, Georgia \\ ${ }^{2}$ College of Education, Auburn University, Auburn, Alabama \\ Correspondence: Jennifer L. Brown, Department of Teacher Education, Columbus State University, 4225 University \\ Avenue, Columbus, Georgia 31907-5645
}

Received: July 29, 2015

doi:10.11114/ijsss.v3i6.986
Accepted: August 11, 2015

Available online: August 28, 2015

URL: http://dx.doi.org/10.11114/ijsss.v3i6.986

\begin{abstract}
According to the Youth Risk Behavior Survey, nearly half of high school seniors have had sexual intercourse. This early sexual involvement may have negative consequences on the adolescent's personality system, behavior system, and environment system has been posited. This study clearly supported this assertion with regard, specifically, to school achievement. While causality cannot be confirmed, a strong relationship was found between school achievement and beliefs favoring abstinence. High achieving youths in this study see the gains to be realized from abstinence is indicated by their self-reported agreement with abstaining from sex, even until marriage. Conversely, the low achieving youths seem not to be realizing the negative consequences associated with early sexual involvement. Educational outcomes certainly seem to be associated with choices made by youths regarding their sexual behavior and intentions. Abstinence education interventions may be an important addition to education of quality.
\end{abstract}

Keywords: Educational attainment, sexual abstinence, school achievement, middle school

\section{Introduction}

\subsection{The Problem}

The results of the Youth Risk Behavior Survey (Centers for Disease Control and Prevention [CDC], 2014) indicated that the percentage of high school students who had ever had sexual intercourse has declined from $54.1 \%$ in 1991 to $46.8 \%$ in 2013. Among 20 large urban districts across 13 states, the percentage ranged from $25.8 \%$ to $59 \%$. Likewise, the percentage of students who had had sexual relations before the age of 13 fell from $10.2 \%$ in 1991 to $5.6 \%$ in 2013. This decrease in early sexual activity may be seen as positive for a number of researchers (Finer, Darroch, \& Singh, 1999; Shrier, Emans, Woods, \& DuRant, 1996; Smith, 1997) who have found that youths who delay their first sexual experience are likely to have fewer sexual partners. According to CDC (2014), 28.1\% of ninth grade females and $32.0 \%$ of ninth grade males have never had sexual intercourse. These percentage dramatically increase by 12 th grade to $62.8 \%$ of females and $65.4 \%$ of males. Given the need to delay initial sexual activity as a strategy for preventing teen pregnancy and sexual transmitted diseases, these statistics clearly show that there is a problem.

Furthermore, according to the 2009 National Youth Risk Behavior Survey data, 69\% of high school students who indicated sexual activity also reported making mostly D's and F's in school. On the other end of the spectrum, only $32 \%$ of high school students who earned mostly A's reported sexual activity (CDC, n. d.). Likewise, the National Campaign to Prevent Teen Pregnancy (2007) speculated that the majority of unplanned pregnancies result in children born to unmarried women. Women with unplanned pregnancies are less likely to receive prenatal care. Thus, their babies are more likely to have low birth weight and to be born prematurely. Subsequently, such children are more likely to have a lower socioeconomic status, lower grade-point averages, and poorer school attendance. Further, they are more likely to drop out of high school, which leads to limited employment and career opportunities.

\subsection{Review of Literature}

Although female youths are less likely to have sexual involvement compared to male youths, those females who have sexual involvement are more likely to earn low grades according to research conducted by Langille and Curtis (2002), Sabia and Rees (2009), and CDC (2014). Orr, Beiter, and Ingersoll (1991) investigated the link between sexual activity 
and other risk behaviors, such as school difficulties, with 1,504 junior high school students. These researchers found that sexually active students had a significantly higher risk of delinquency and school problems. These findings were supported by the research of Gruber and Machamer (2000) with high school students. Those participants who were classified as high risk of educational failure (e.g., low school achievement or dropout) tended to have a higher likelihood for experiencing risk taking behaviors, such as sexual activity, compared to those participants with low or no educational risk. Of those participants who were considered no educational risk, only $33.9 \%$ of them reported involvement in sexual behavior; however, $88.9 \%$ of the participants who were considered high educational risk reported involvement in sexual behavior.

Using a sample of 3,684 females and data from the National Longitudinal Study of Adolescent Health, Sabia and Rees (2012) found as the level of educational attainment increased the number of sexual partners decreased. Schvaneveldt, Miller, Berry, and Lee (2001) found that lower educational goals and school achievement were associated with initiation of sexual intercourse at a younger age. Moreover, when sexual activity was initiated, interest in achievement goals declined. By delaying sexual intercourse for at least one year, the likelihood of a female graduating from high school significantly increased. A gap exist in the current literature as to whether a relationship between sexual abstinence and school achievement exists (Sabia \& Rees, 2009).

\subsection{Purpose of the Study}

The literature does not provide a conclusive position on the relationship between school achievement, which was defined as final academic performance on school-issued report cards, and sexual beliefs and involvement, particularly with middle school students. The purpose of this research study was to investigate further this relationship. Specific research questions were:

1. What is the relationship between self-reported grades and the participants' agreement with selected beliefs about abstinence as a priority?

2. What is the relationship between grade level and the participants' agreement with selected beliefs about abstinence as a priority?

3. Does grade level moderate the relationship between self-reported grades and the participants' agreement with selected beliefs about abstinence as a priority?

\section{Methods}

\subsection{Data Source}

The data source for this study was a sample of 336 students from a rural county located in a southeastern state within the United States participating in an abstinence-only education program funded by Section 510 of Title V of the Social Security Act. The participants included 170 (50.6\%) seventh- and 166 (49.4\%) eighth-grade students. Of these students, $154(45.8 \%)$ were male and $182(54.2 \%)$ were female. The racial makeup of the group was $181(53.9 \%)$ White, 138 $(41.1 \%)$ Black, and $17(5.0 \%)$ students who reported they belonged to other racial groups. For self-reported grades, 110 (32.7\%) reported they earned mostly A's, 102 (30.4\%) reported they earned mostly B's, and $124(36.9 \%)$ reported they earned mostly C's or below in school. More than $51 \%$ of the participants reported they received free or reduced lunch at school. More than $94 \%$ of the participants reported that they planned to attend post-secondary school. In terms of family structure, $128(38.1 \%)$ participants reported that they lived with both parents, and $78(23.2 \%)$ participants reported they lived in a single-parent household. The remaining $38.7 \%$ of the participants reported living with stepparents, grandparents, or extended family members.

\subsection{Data Collection Procedure}

The Youth Survey (Halpin \& Halpin, 1998) was administered to the sample of 336 students in their respective classrooms. Prior to administering the surveys, the Abstinence Educator filled out a unique code for each participant, which included grade level on the Youth Survey answer sheets. These answer sheets were distributed to the participants along with the Youth Survey booklets at the beginning of the class period. Before beginning the survey, participants were informed that the information collected with this survey would be kept confidential, and they were asked to be as truthful as possible. The Youth Survey was read aloud to the participants as they followed along and answered the questions. After the questions were read, the meanings of some questions were clarified for the participants by asking the question with simplified wording.

\subsection{Measures}

The Youth Survey (Halpin \& Halpin, 1998), which consisted of 76 items, was the measurement tool used in this study. The beginning questions elicited demographic information and established an initial baseline of sexual activity among the respondents. On the majority of the other items, respondents were asked to indicate the extent of their agreement 
using a 4-point scale. The response scale progressed from a rating of 1, which represented the most positive response of Strongly Agree, to a rating of 4, which represented the least positive response of Strongly Disagree. These items were rationally combined to form scales that measured the eight legislative priorities as defined by Section 510 of Title V of the Social Security Act. Understandings related to each of the eight legislative priorities assessed were as follows:

(a) There are social, psychological, and health gains to be realized by abstaining from sexual activity;

(b) Abstinence from sexual activity outside of marriage is the expected standard for all school-age children;

(c) Abstinence from sexual activity is the only certain way to avoid out-of-wedlock pregnancy;

(d) A mutually faithful and monogamous relationship in the context of marriage is the expected standard of human sexual activity;

(e) Sexual activity outside of the context of marriage is likely to have harmful psychological and physical effects;

(f) Bearing children out of wedlock is likely to have harmful consequences for the child, the child's parents, and society;

(g) Sexual advances can be rejected and that alcohol and drug use increase vulnerability to sexual advances;

(h) Attaining self-sufficiency is vital before engaging in sexual activity.

In order to be confident that these scales provide accurate measurements, reliability analyses were conducted. Results for the reliability analyses are presented in Table 1. With Cronbach's alpha of .50 or greater as a criterion, these results suggest that the scales within the survey are internally consistent measures (ranged from .65 to .89). Given these analyses indicating that the Youth Survey measures are reliable, subsequent analyses were justified.

Table 1. Alpha Reliability Coefficients for the Legislative Priority Scales

\begin{tabular}{lc}
\hline Scale & Coefficient \\
\hline Legislative Priority A & .81 \\
Legislative Priority B & .87 \\
Legislative Priority C & .65 \\
Legislative Priority D & .77 \\
Legislative Priority E & .79 \\
Legislative Priority F & .65 \\
Legislative Priority G & .75 \\
Legislative Priority H & .89 \\
\hline
\end{tabular}

\section{Results}

\subsection{Research Question 1}

Data were analyzed using multivariate analysis of variance with follow-up univariate analyses to determine the relationship between self-reported grades and the participants' agreement with selected beliefs about abstinence as a priority. The results indicated that the means of the optimally weighted combination of scores for the legislative priority scales differed significantly by self-reported grades, $F(16,648)=4.59 ; p<.001 ; \eta^{2}=.10$. The follow-up univariates were significant for all eight legislative priorities. These results support the notion that agreement with the legislative priorities differs for participants who reported earning mostly A's and for participants who reported earning mostly B's and C's. The means, standard deviations, and GLM univariates are presented in Table 2. A Bonferroni pairwise comparison revealed that all combinations were significant except between mostly A's and mostly B's for Legislative Priorities A, B, D, F, G, and H.

Table 2. Means, Standard Deviations, and GLM Univariates by Self-Reported Grades

\begin{tabular}{|c|c|c|c|c|c|c|c|c|c|}
\hline & \multicolumn{2}{|c|}{$\underline{\text { Mostly A's }}$} & \multicolumn{2}{|c|}{$\underline{\text { Mostly B's }}$} & \multicolumn{2}{|c|}{$\frac{\text { Mostly C's and }}{\text { below }}$} & \multirow[b]{2}{*}{$F$} & \multirow[b]{2}{*}{$p$} & \multirow[b]{2}{*}{$\eta 2$} \\
\hline Scale & $M$ & $S D$ & $M$ & $S D$ & $M$ & $S D$ & & & \\
\hline Legislative Priority A & 1.52 & 0.45 & 1.68 & 0.48 & 1.92 & 0.49 & 20.22 & .00 & .11 \\
\hline Legislative Priority B & 1.64 & 0.51 & 1.83 & 0.55 & 2.16 & 0.50 & 29.25 & .00 & .15 \\
\hline Legislative Priority C & 1.45 & 0.43 & 1.60 & 0.40 & 1.75 & 0.48 & 12.79 & .00 & .07 \\
\hline Legislative Priority D & 1.44 & 0.49 & 1.53 & 0.45 & 1.75 & 0.52 & 11.00 & .00 & .06 \\
\hline
\end{tabular}




\begin{tabular}{llllllllll} 
Legislative Priority E & 1.55 & 0.50 & 1.75 & 0.54 & 1.93 & 0.55 & 13.94 & .00 & .08 \\
Legislative Priority F & 1.70 & 0.41 & 1.83 & 0.43 & 2.04 & 0.45 & 18.18 & .00 & .10 \\
Legislative Priority G & 1.52 & 0.48 & 1.57 & 0.48 & 1.83 & 0.48 & 13.99 & .00 & .08 \\
Legislative Priority H & 1.51 & 0.54 & 1.67 & 0.61 & 1.96 & 0.61 & 17.24 & .00 & .10 \\
\hline
\end{tabular}

3.2 Research Question 2

Data were analyzed using multivariate analysis of variance with follow-up univariate analyses to determine the relationship between grade level and the participants' agreement with selected beliefs about abstinence as a priority. The results of the multivariate analysis indicated that the means of the optimally weighted combination of scores for the eight legislative priority scales differed significantly by grade level, $F(8,323)=4.64 ; p<.001 ; \eta^{2}=.10$. These results lend credence to the notion that seventh- and eighth-grade students differed in their agreement with the legislative priorities. The follow-up univariate analyses revealed that seventh-grade participants differed significantly from the eighth-grade participants on Legislative Priorities A, B, D, E, G, and H. The means, standard deviations, and GLM univariates are presented in Table 3.

Table 3. Means, Standard Deviations, and GLM Univariates by Grade Level

\begin{tabular}{lccccrcc}
\hline & \multicolumn{2}{c}{ Grade 7 } & \multicolumn{2}{c}{ Grade 8 } & & \\
Scale & $M$ & $S D$ & $M$ & $S D$ & \multicolumn{1}{c}{$\eta_{2}$} \\
\hline Legislative Priority A & 1.63 & 0.49 & 1.80 & 0.50 & 9.55 & .00 & .03 \\
Legislative Priority B & 1.77 & 0.54 & 2.01 & 0.56 & 16.82 & .00 & .05 \\
Legislative Priority C & 1.60 & 0.47 & 1.62 & 0.45 & 0.02 & .88 & .00 \\
Legislative Priority D & 1.51 & 0.47 & 1.66 & 0.54 & 7.21 & .01 & .02 \\
Legislative Priority E & 1.63 & 0.50 & 1.88 & 0.57 & 16.29 & .00 & .05 \\
Legislative Priority F & 1.82 & 0.44 & 1.91 & 0.46 & 2.48 & .12 & .01 \\
Legislative Priority G & 1.57 & 0.46 & 1.73 & 0.52 & 7.62 & .01 & .02 \\
Legislative Priority H & 1.55 & 0.54 & 1.90 & 0.64 & 27.59 & .00 & .08 \\
\hline
\end{tabular}

3.3 Research Question 3

Data were analyzed using multivariate analysis of variance with follow-up univariate analyses to determine whether grade level moderates the relationship between self-reported grades and the participants' agreement with selected beliefs about abstinence as a priority. The results indicated that the means of the optimally weighted combination of scores for the legislative priority scales did not differ significantly by self-reported grades within grade level, $F(16,648)$ $=1.12 ; p=.33 ; \eta^{2}=.03$. The follow-up univariate analyses were not applicable because there was not a significant interaction effect. The means, standard deviations, and GLM univariates by self-reported grades within grade level are presented in Table 4.

Table 4. Means, Standard Deviations, and GLM Univariate Tests by Grade Level Within Self-Reported Grades

\begin{tabular}{|c|c|c|c|c|c|c|c|c|c|c|c|c|c|c|c|}
\hline \multirow[b]{3}{*}{ Scale } & \multicolumn{6}{|c|}{ Grade 7} & \multicolumn{6}{|c|}{ Grade 8} & \multirow[b]{3}{*}{$F$} & \multirow[b]{3}{*}{$p$} & \multirow[b]{3}{*}{$\eta^{2}$} \\
\hline & \multicolumn{2}{|c|}{$\underline{\text { Mostly A's }}$} & \multicolumn{2}{|c|}{ Mostly B's } & \multicolumn{2}{|c|}{$\frac{\text { Mostly C's }}{\text { and below }}$} & \multicolumn{2}{|c|}{ Mostly A's } & \multicolumn{2}{|c|}{ Mostly B's } & \multicolumn{2}{|c|}{$\frac{\text { Mostly C's }}{\underline{\text { and below }}}$} & & & \\
\hline & $M$ & $S D$ & $M$ & $S D$ & $M$ & $S D$ & $M$ & $S D$ & $M$ & $S D$ & $M$ & $S D$ & & & \\
\hline & 1.40 & 0.34 & 1.62 & 0.50 & 1.86 & 0.51 & 1.67 & 0.52 & 1.72 & 0.47 & 1.97 & 0.46 & 1.21 & .30 & .01 \\
\hline & .51 & 0.37 & 1.74 & 0.59 & 2.05 & 0.53 & 1.81 & 0.62 & 1.90 & 0.52 & 2.27 & 0.43 & 0.47 & .62 & .00 \\
\hline & 1.42 & 0.42 & 1.65 & 0.44 & 1.73 & 0.48 & 1.49 & 0.44 & 1.56 & 0.37 & 1.77 & 0.48 & 0.88 & .42 & .01 \\
\hline & 1.34 & 0. & 1.49 & 0.46 & 1.68 & 0. & 58 & 0 & 1.56 & 0.45 & 1.81 & 0.52 & 0.80 & .45 & .01 \\
\hline & 41 & 0.37 & 1.73 & 0.52 & 1.77 & 0.52 & 1.74 & 0.58 & 1.77 & 0.55 & 2.09 & 0.53 & 2.79 & .06 & .02 \\
\hline Legisla & 1.68 & 0.39 & 1.80 & 0.39 & 1.98 & 0.49 & 1.72 & 0.44 & 1.86 & 0.47 & 2.10 & 0.40 & 0.26 & .77 & .00 \\
\hline $\begin{array}{l}\text { Legis } \\
\text { Priori }\end{array}$ & 45 & 0.41 & 1.53 & 0.46 & 1.72 & 0.48 & 1.60 & 0.56 & 1.60 & 0.49 & 1.94 & 0.46 & 0.71 & .50 & .00 \\
\hline $\begin{array}{l}\text { Legislative } \\
\text { Priority H }\end{array}$ & 1.37 & 0.38 & 1.52 & 0.55 & 1.77 & 0.60 & 1.69 & 0.66 & 1.80 & 0.63 & 2.14 & 0.57 & 0.17 & .85 & .00 \\
\hline
\end{tabular}




\section{Discussion}

Years ago, Billy, Landale, Grady, and Zimmerle (1988) posited that early sexual involvement may have negative consequences on the adolescent's personality system, behavior system, and environment system. This study clearly supported this assertion. While causality cannot be confirmed, the strong relationship found in this study between beliefs favoring abstinence and school achievement strongly supports a directional hypothesis supporting abstinence. That is, the high achieving youths see the gains to be realized from abstinence is indicated by their self-reported agreement with the Title $\mathrm{V}$ legislative priorities advancing abstinence. Conversely, the low achieving youths do not espouse the same beliefs regarding abstinence. Educational outcomes certainly seem to be related to choices made by youth regarding their sexual behavior and intentions. Abstinence education interventions may be an important addition to education of quality.

There were some limitations to this study. First, the grades were self-reported by the participants. It would be difficult to capture actual grades and maintain the anonymity of the participants. Second, the Youth Survey was administered one time only without follow-up measures. Further research could examine the changes among the participants' agreement with the eight legislative priorities in addition to the frequency of sexual involvement over time by administering follow-up measures. In addition, future studies could examine youth from urban areas within the United States.

\section{References}

Billy, J. O. G., Landale, N. S., Grady, W. R., \& Zimmerle, D. D. (1988). Effects of sexual activity on adolescent social and psychological development. Social Psychology Quarterly, 51, 190-212. http://dx.doi.org/10.2307/2786919

Centers for Disease Control and Prevention. (2014). Youth risk behavior surveillance - United States, 2013. Morbidity and Mortality Weekly Report, 63(4). Retrieved from http://www.cdc.gov/mmwr/pdf/ss/ss6304.pdf

Centers for Disease Control and Prevention. (n.d.). Sexual risk behaviors and academic achievement. Washington, DC: US Department of Health and Human Services, Division of Adolescent and School Health. Retrieved from http://www.cdc.gov/healthyyouth/health_and_academics/pdf/sexual_risk_behaviors.pdf

Finer, L. B., Darroch, J. E., \& Singh, S. (1999). Sexual partnership patterns as a behavioral risk factor for sexually transmitted diseases. Family Planning Perspectives, 31, 228-236. http://dx.doi.org/10.2307/2991570

Gruber, E., \& Machamer, A. M. (2000). Risk of school failure as an early indicator of other health risk behaviour in American high school students. Health, Risk, \& Society, 2, 59-68. http://dx.doi.org/136985700111459

Halpin, G., \& Halpin, G. (1998). Youth Survey: Version L. Auburn, AL: Auburn University.

Langille, D. B., \& Curtis, L. (2002). Factors associated with sexual intercourse before age 15 among female adolescents in Nova Scotia. The Canadian Journal of Human Sexuality, 11, 91-99.

National Campaign to Prevent Teen Pregnancy. (2007). Preventing unplanned and teen pregnancy: Why it matters. Washington, DC: National Campaign to Prevent Teen Pregnancy. http://www.thenationalcampaign.org/whyit-matters.

Orr, D. P., Beiter, M., \& Ingersoll, G. (1991). Premature sexual activity as an indicator of psychosocial risk. Pediatrics, 87, 141-147.

Sabia, J. J., \& Rees, D. I. (2009). The effect of sexual abstinence on educational attainment. Demography, 46(4), 695-715. http://dx.doi.org/ 10.1353/dem.0.0072

Sabia, J. J., \& Rees, D. I. (2012). Does the number of sex partners affect educational attainment? Evidence from female respondents on the add health. Journal of Population Economics, 25, 89-110. http://dx.doi.org/10.1007/s00148-011-0354-z

Schvaneveldt, P. L., Miller, B. C., Berry, E. H., \& Lee, T R. (2001). Academic goals, achievement, and age of first sexual intercourse: Longitudinal, bidirectional influences. Adolescence, 35(144), 767-787.

Shrier, L. A., Emans, S. J., Woods, E. R., \& DuRant, R. H. (1996). The association of sexual risk behaviors and problem drug behaviors in high school students. Journal of Adolescent Health, 20, 337-383.

Smith, C. A. (1997). Factors associated with early sexual activity among urban adolescents. Social Work, 42(4), 334-346. http://dx.doi.org/ 10.1093/sw/42.4.334

\section{$(\mathrm{Cc}))_{\mathrm{BY}}$}

This work is licensed under a Creative Commons Attribution 3.0 License. 